\title{
Efectos de la adición de ácido cítrico y un probiótico comercial en el agua de bebida, sobre la morfometría del duodeno y parámetros zootécnicos en pollo de engorde
}

\section{The effect of adding citric acid and a commercial probiotic to drinking water on the morphometry of the duoden um for broilers and their zootechnical parameters}

\section{Efeitos da adição de ácido cítrico e um probiótico comercial em água potável na morfometria duodenal e parâmetros zootécnicos em frango de corte de reprodução}

\section{Helena María Barrera-Barrera ${ }^{1}$, Sandra Paola Rodríguez-González ${ }^{2}$, Giovanny Torres- Vidales ${ }^{3}$}

MVZ, MSc, Universidad Pedagógica y Tecnológica de Colombia.

MVZ, MSc, Docente Fundación Universitaria Juan de Castellanos, Tunja.

MVZ, Esp, Profesor asistente Universidad Pedagógica y Tecnológica de Colombia.

Email: srodriguez@jdc.edu.co

Aceptado: Julio 9 de 2014.

\section{Resumen}

El objetivo de este trabajo fue evaluar el efecto de la adición de ácido cítrico y un probiótico comercial en el agua de bebida, sobre el desarrollo pos-eclosión del duodeno y parámetros productivos en pollos de engorde. Se utilizaron 102 aves de la estirpe Ross, machos, de un día de edad, distribuidos por un método completamente al azar, en tres tratamientos: Grupo A: agua y $0.5 \%$ de ácido cítrico/ave. Grupo B: agua y $0.3 \mathrm{ml}$ del producto comercial. Grupo C: agua sin aditivos. Las aves se mantuvieron bajo condiciones iguales de manejo, alojamiento y sanidad. Por el método aleatorio se seleccionaron individuos en los días 1, 7, 15 y 35 de edad; se tomaron muestras de duodeno, las cuales se procesaron según la técnica descrita para la coloración de hematoxilina-eosina $(\mathrm{H}-\mathrm{E})$. Para la evaluación del comportamiento morfométrico, se contaron las vellosidades por campo de microscopio. Las mediciones de longitud y amplitud fueron tomadas desde la lámina basal, hasta el ápice y el ancho, en el centro de cada una, utilizando un objetivo de 4X. Se presentaron diferencias significativas $(p<0.05)$ para las variables morfométricas de cantidad, longitud y ancho de las vellosidades y para los parámetros zootécnicos, a favor del grupo suplementado con el probiotico comercial, en el agua de bebida. El uso de probióticos desde el primer día de edad en pollos de engorde, favorece el desarrollo pos-eclosión de la morfometría duodenal y los parámetros zootécnicos en este tipo de producción.

Palabras claves: ave, ácido cítrico, probiótico, alometría intestinal. 


\begin{abstract}
This work dealt with evaluating the effect of adding citricacid and a commercial probiotic to drinking water on broilers' duodenum development post-hatching and production parameters. The study involved using 102 male, one-day-old Ross broilers, distributed into three treatments by a completely random method: group A received water and $0.5 \%$ citric acid /bird, group B water and $0.3 \mathrm{ml}$ commercial product and group $C$ water with no additives. The birds were kept in similar handling, housing and sanitation conditions; the random method involved selecting individuals aged 1, 7, 15 and 35 days' old. Samples were taken from the duodenum and processed by the haematoxylin-eosin $(\mathrm{H}-\mathrm{E})$ staining technique. Villi within the microscopic field were counted for evaluating morphometric patterns; length and amplitude were measured from the basal lamina to the apex and breadth in the centre of each one, using a 4X objective.
\end{abstract}

There were significant differences $(p<0.05)$ regarding morphometric variables for the amount of villi and their length and breadth and concerning zootechnical parameters for the group supplemented with commercial probiotic indrinking water. Using probiotics from the first day of age on broilers favoured post-hatching development of duodenal morphometry and zootechnical parameters on this type of production.

Key words: broiler, citric acid, probiotic, intestinal allometry.

\title{
Resumo
}

O objetivo deste estudo foi avaliar o efeito da adição de ácido cítrico e um probiótico comercial na água de bebida no desenvolvimento pós eclosão de duodeno e parâmetros produtivos em frangos de corte. 102 aves machas da linhagem Ross, de um dia de idade, distribuídos por um método completamente aleatório foi usado, da seguinte forma: Grupo A: água e 0,5\% de ácido cítrico / ave, Grupo B: água e 0,3 ml do produto comercial, Grupo C: água sem aditivos; aves foram mantidas sob as mesmas condições de manejo, alojamento e saúde; pelo método ao acaso os indivíduos foram seleccionados nos dias 1, 7, 15, e 35 de idade; Amostras duodenais foram tomadas, as quais foram processadas de acordo com a técnica descrita para a coloração de hematoxilina-eosina $(\mathrm{H}-\mathrm{E})$. Para avaliação do comportamento morfométrico, as vilosidades foram contadas por campo microscópio, as medidas de comprimento e largura foram retiradas da lâmina basal até o ápice, ea largura no centro de cada uma utilizando uma objectiva de 4X.

Houve diferenças significativas $(p<0,05)$ para as variáveis morfométricas de quantidade, comprimento e largura das vilosidades e parâmetros zootécnicos em favor do grupo suplementado com probiótico comercial em água potável. O uso de probióticos desde o primeiro dia de idade dos frangos de corte ajuda no desenvolvimento póseclosão da morfometria duodenal e os parâmetros zootécnicos neste tipo de produção.

Palavras-chave: aves, ácido cítrico, probiótico, alometria intestinal. 


\section{Introducción}

Al nacimiento, el aparato digestivo del feto (mamíferos) o del embrión (aves) es estéril (Millán, et al. 2007). Tras la eclosión del huevo, las aves no están preparadas para afrontar el entorno que les rodea. Durante el desarrollo embrionario, el huevo les proporciona los nutrientes que necesitan y tras la eclosión, el resto de la yema que funciona como remanente en la cavidad abdominal, les proporciona un pequeño aporte de nutrientes. Este suplemento nutritivo es reabsorbido en los 4 ó 5 primeros días de vida (Sell, 2009).

La longitud del intestino aumenta durante la primera semana de vida, incluso en la ausencia de alimento; sin embargo, el consumo de éste, es esencial para el inicio del desarrollo de las vellosidades intestinales. A las dos semanas de edad el intestino tiene plena capacidad digestiva y absortiva. Cinco días antes de la eclosión, las vellosidades intestinales comienzan gradualmente a alargarse, alcanzando su máximo a los seis días de edad en el duodeno y 10 días de edad en yeyuno e íleon. El volumen de las mismas alcanzan su máximo entre 10 y 15 días después de la eclosión (González, 2010).

El desarrollo y la salud del tracto gastrointestinal son elementos clave en la producción del pollo de engorde; factores como los estímulos inmunitarios, el medio ambiente, la nutrición, la calidad de los ingredientes de la ración, el equilibrio de la microflora, las secreciones endógenas, la motilidad y los aditivos, entre otros, influyen en el desempeño de la producción. Según Gauthier (2002), se puede considerar que las disfunciones digestivas constituyen los factores más limitantes para el rendimiento.

Según Saikat, et al., (2009) para mejorar los factores del desarrollo gastrointestinal, se ha encontrado que las condiciones ácidas favorecen la absorción de nutrientes y mejoran la funcionalidad del intestino. Al mismo tiempo algunos ácidos penetran en la célula bacteriana, causando un desequilibro interno, promoviendo su destrucción; esta capacidad se pone especialmente de manifiesto en los pollos de engorde. La suplementación con ácido cítrico a $0,5 \%$ en la dieta, ha tenido efecto positivo sobre el crecimiento, consumo de ración, eficiencia alimenticia, ceniza ósea, y sobre el estatus inmunitario de pollos de engorde. Por consiguiente, el ácido cítrico puede ser un aditivo útil en lugar de los antibióticos promotores de crecimiento (Chowdhury, et al., 2009, Gómez y Hernández. 2009).

El empleo de probióticos en las aves está encaminado a mejorar el balance microbiano del Tracto Gastrointestinal (TGI), inhibir el crecimiento de bacterias dañinas, producir enzimas hidrolíticas para mejorar la utilización de los alimentos y como resultado final, mejorar los rendimientos productivos (Millán, et al., 2007. Sarker, et al., 2010). El ácido cítrico y los probióticos han demostrado tener un beneficio en la salud intestinal, de hecho, mejoran la cantidad de células y en consecuencia, el número y tamaño de las vellosidades intestinales (Furlan, et al., 2004). Significa entonces que la utilización de productos de origen biológico para el desarrollo pecuario, busca cada vez más el beneficio ecológico debido a que su uso, no genera daño al medio ambiente y se generan productos inocuos (Palencia, etal., 2005).

Por otra parte, utilizando suplementos de probióticos, Ignatova et al. (2009) han reportado efectos positivos sobre el peso corporal final en un $14,4 \%$, además de mayor consumo de alimento en $7,7 \%$; y la utilización alimenticia mejoró 8,1\%. Las formas de acción de los probióticos a nivel intestinal, radican en la remoción o eliminación de agentes patógenos entéricos a través de la producción de sustancias con actividad antimicrobiana, la supresión de la producción 
de toxinas mediante la inhibición de la actividad metabólica de las bacterias que las producen, y la estimulación de mecanismos de defensa y la inmunidad inespecífica (Lessard, 2004).

Los acidificantes mejoran la funcionalidad intestinal y promueven mayor control del crecimiento de microorganismos sensibles, favorece las condiciones ecológicas intestinales; y además, aumenta el consumo de alimento diario, reduciendo la mortalidad en la etapa de producción (Gómez y Hernández, 2009; Ramírez y Blanco, 2009). Adicionalmente, los ácidos orgánicos como el cítrico, propiónico, fumárico, y fórmico, producen un aumento de la proteólisis gástrica y la digestibilidad de proteínas y aminoácidos. El objetivo de este trabajo fue evaluar el efecto de la adición de ácido cítrico y un probiotico comercial, en el agua de bebida sobre el desarrollo del duodeno y algunos parámetros productivos en pollos de engorde.

\section{Materiales y métodos}

\section{Sitio de estudio}

El trabajo se realizó en la ciudad de Sogamoso, Boyacá, situada en el centro-oriente de Colombia, a $213 \mathrm{~km}$ de Bogotá, en la región del Alto Chicamocha a $2.569 \mathrm{~m}$ de altitud, posee una temperatura cuyo promedio es de $20{ }^{\circ} \mathrm{C}$.

(http://sogamoso-boyaca.gov.co /informacion _general.shtml\#geografia)

\section{Selección de animales}

Se manejaron 102 pollos machos, de las estirpes Ross de un día de edad, provenientes de una misma incubadora, un mismo lote y edad de reproductoras. Se recibieron con la vacuna de Marek-Gumboro; las aves se seleccionaron por un método al azar, se ubicaron en tres grupos de 34 aves, de 8 y 9 animales, con cuatro replicas por grupo, en tres espacios del mismo diámetro. Se hizo en condiciones iguales de manejo, alojamiento y sanidad.

Una vez ubicadas las aves, se asignaron los tratamientos de la siguiente manera:

Grupo A: Agua + 0.5\% /L de Ácido Cítrico

Grupo B: Agua y $0.3 \mathrm{ml} / \mathrm{L}$ de Probiótico comercial

Grupo C: Agua sin aditivos

Al total de los grupos, se les suministro el mismo tipo de alimento, concentrado comercial propio para la etapa productiva y según indicaciones de la guía de manejo para la estirpe.

\section{Toma de muestras}

Por el método aleatorio se seleccionaron las aves a muestrear en cada grupo, se pesaron in vivo en horas de la mañana antes de suministrar el alimento, los días que corresponde a las fechas destinadas para sacrificio $(1,7,15,35)$; se tomaron 12 muestras en total, es decir 4 por cada grupo, obteniéndose 48 muestras en el periodo experimental.

Se procedió al sacrificio de las aves por el método de electrocución y siguiendo la técnica de necropsia convencional, se tomaron muestras de la porción craneal del duodeno, que se fijaron en formol al 10\%. Se procesaron según la técnica de rutina para la coloración de hematoxilina-eosina (H-E), previa inclusión en bloques de parafina.

Una vez obtenidas las láminas se evaluaron utilizando un microscopio óptico Modelo dmwb1 - 223 digital marca Motic $®$, que se encuentra en el Laboratorio de Ciencias 
Básicas de la Fundación Universitaria Juan de Castellanos, en la ciudad de Tunja. Para obtener los datos del comportamiento alométrico se contaron las vellosidades y tomaron mediciones de longitud y amplitud de las mismas, utilizando un objetivo de 4X. Los resultados obtenidos son el valor promedio de cuatro campos evaluados.

Para el parámetro de longitud, se tomó desde la base de la vellosidad ubicada en límite con la serie de criptas de lieberkÜnth, hasta el ápice que se encuentra hacia el lumen del órgano. Para la amplitud fue medida la parte basal y la escala de medición se determinó en $\operatorname{micras}(\mu \mathrm{m})$.

\section{Análisis estadístico}

Los resultados obtenidos se consolidaron en una base de datos simple utilizando el programa Microsoff Office Excel versión 2007; se analizaron con el Test de Fisher y el análisis de varianzas se hizo a través del programa SPSS Versión 11.0.

\section{Resultados}

En el día 1 de edad, el efecto del suplemento de ácido cítrico y probióticos en el agua de bebida, sobre la cantidad de las vellosidades del duodeno, no se encontraron diferencias significativas. Sin embargo, para el día 15, la cantidad de vellosidades fue superior para el grupo control, tal como se evidencia en la Figura 1. Un hallazgo relevante es la presencia de vellosidades en forma de zigzag en el día 7, en el grupo suplementado con probiótico. (Figura 2)

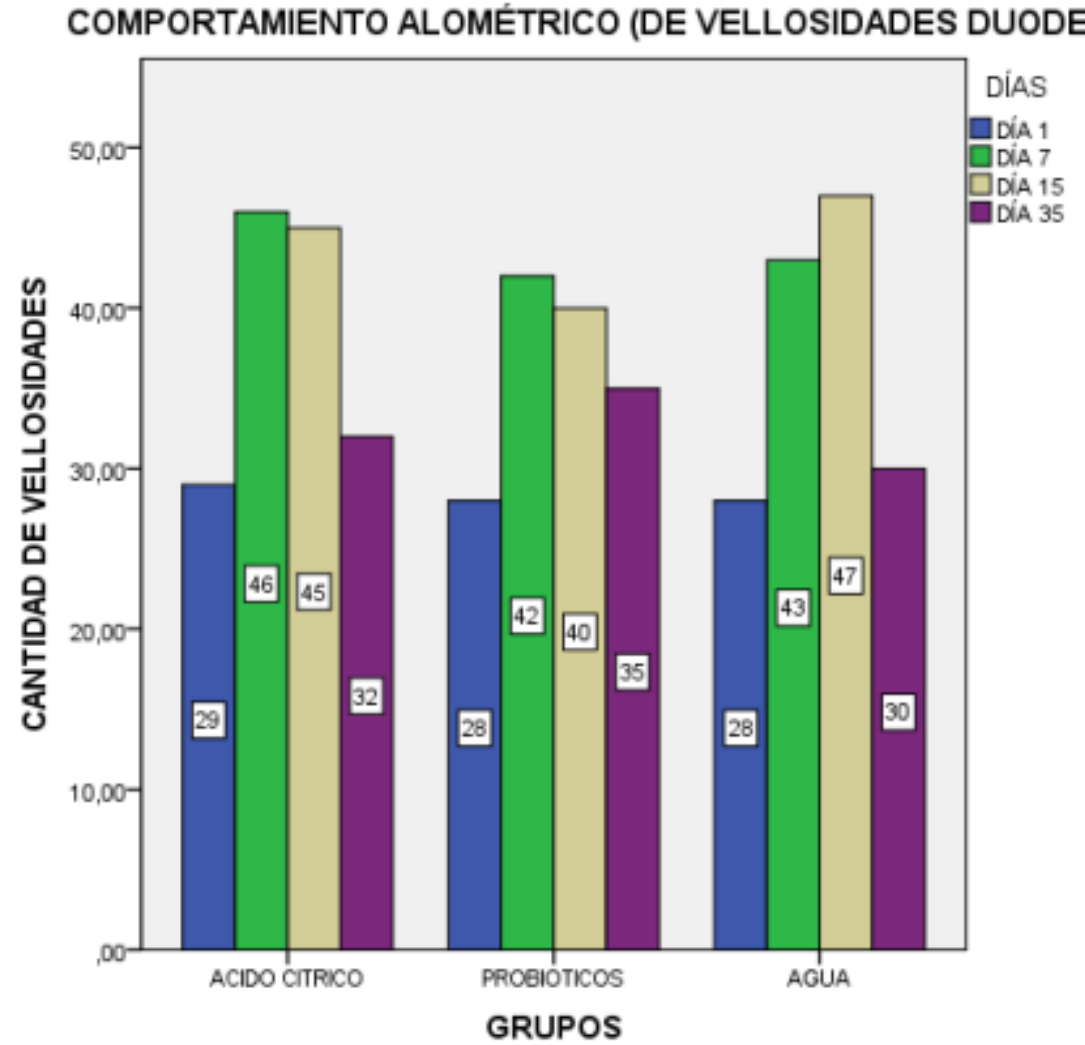

Figura 1. Comportamiento alométrico para la cantidad de vellosidades duodenales 

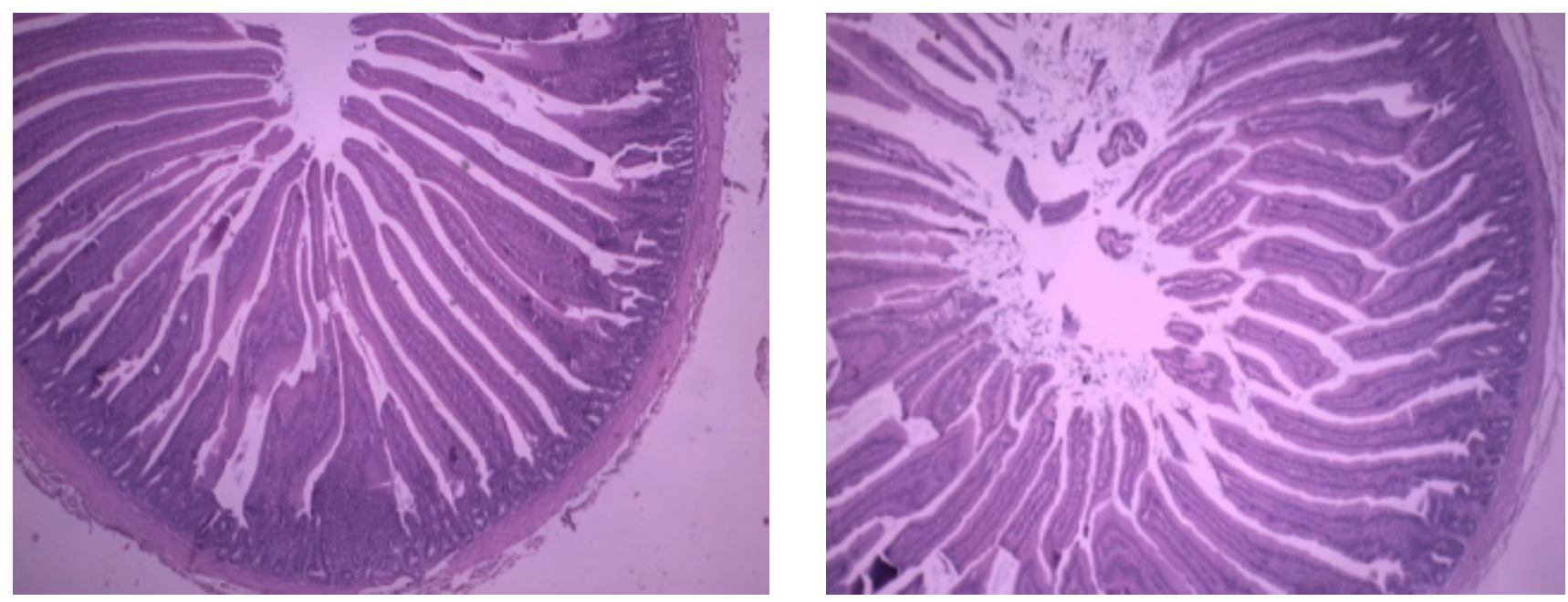

Figura 2. Corte histológico de duodeno, día 7 edad, con aumento de 4X. A. Vellosidades en forma de lengüeta en grupo control. B. Vellosidades en forma de zigzag para el grupo con probiotico comercial.

La longitud en promedio de las vellosidades duodenales, con el suplemento de probióticos y ácido cítrico en dietas de pollos de engorde, se muestra en la Figura 3. Durante el tiempo de estudio se presentó mejor longitud en el grupo de aves suplementado con probiotico comercial.

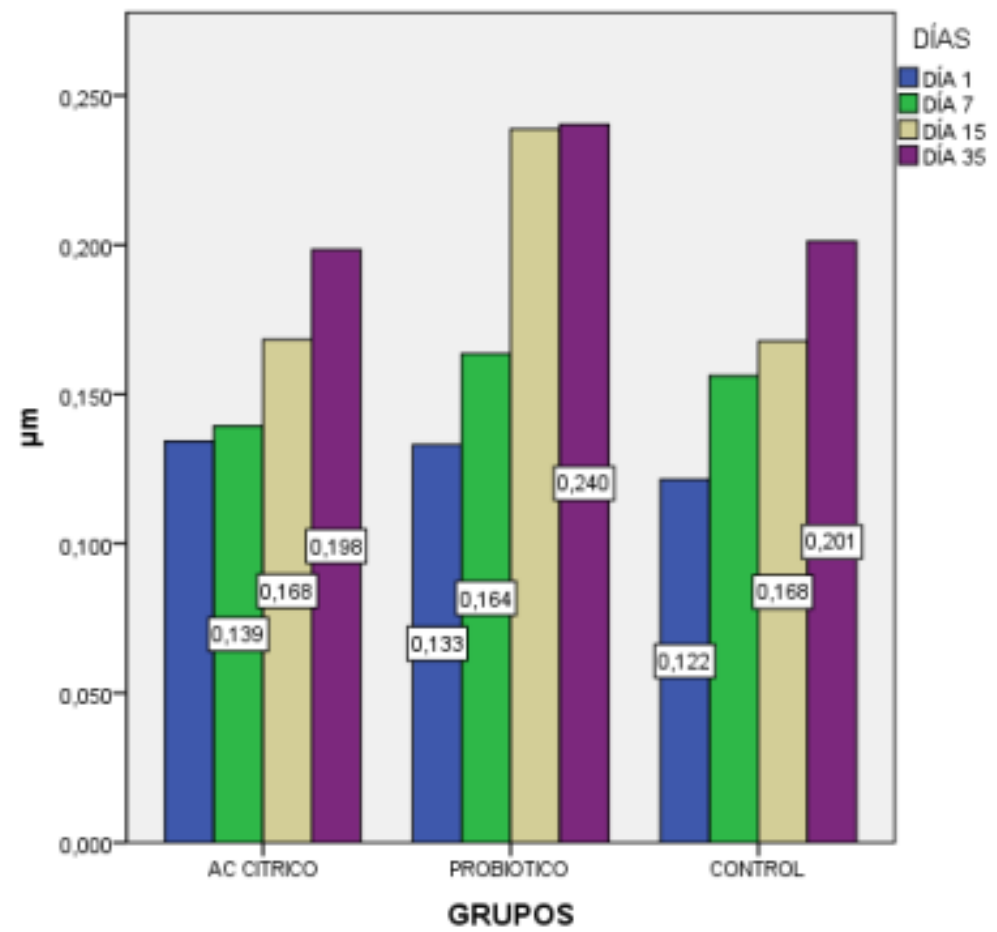

Figura 3. Promedio de longitud de las vellosidades duodenales en pollos de engorde.

El uso en el agua de bebida de ácido cítrico o probióticos, incrementó el área de amplitud de las vellosidades duodenales $(p>0,05)$ frente al grupo control. Efecto que se presentó durante el tiempo de experimento (Figura 4). 


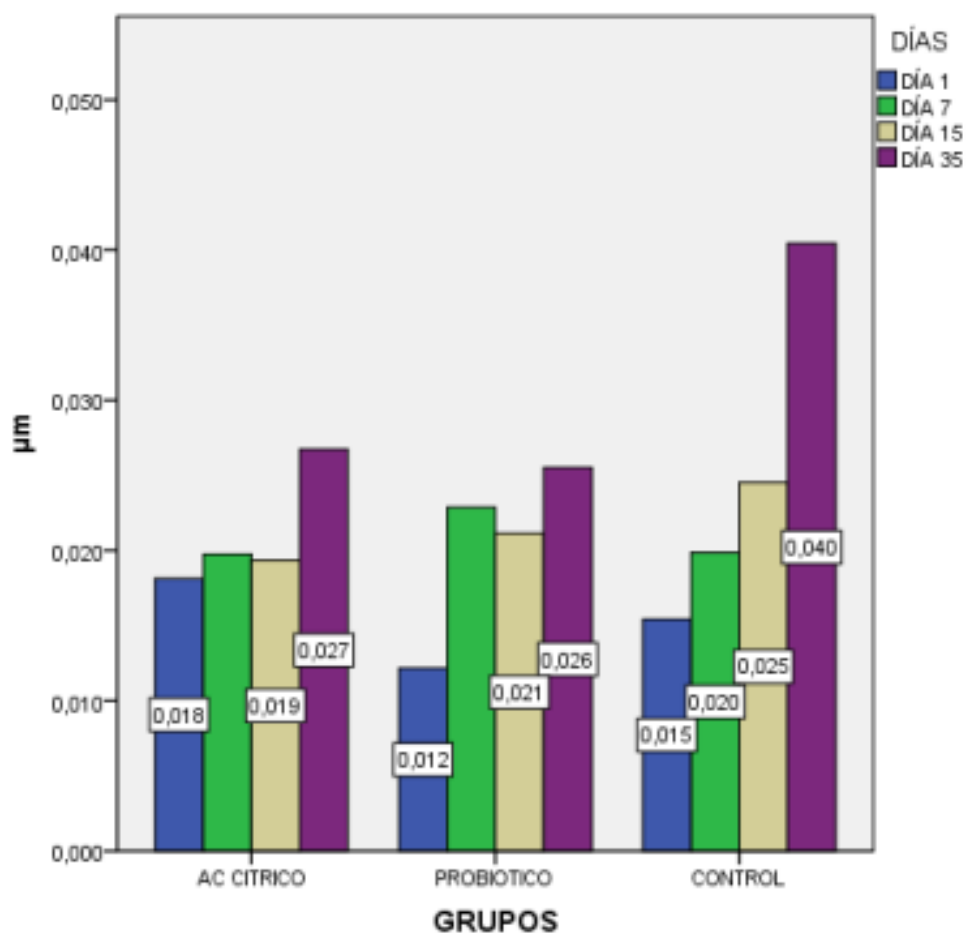

Figura 4. Promedio de la amplitud de las vellosidades duodenales en pollos de engorde

En cuanto a la ganancia de peso, los mejores resultados se presentaron en las aves a las cuales se les adicionó probiótico en el agua, tal como se observa en la Figura 5.

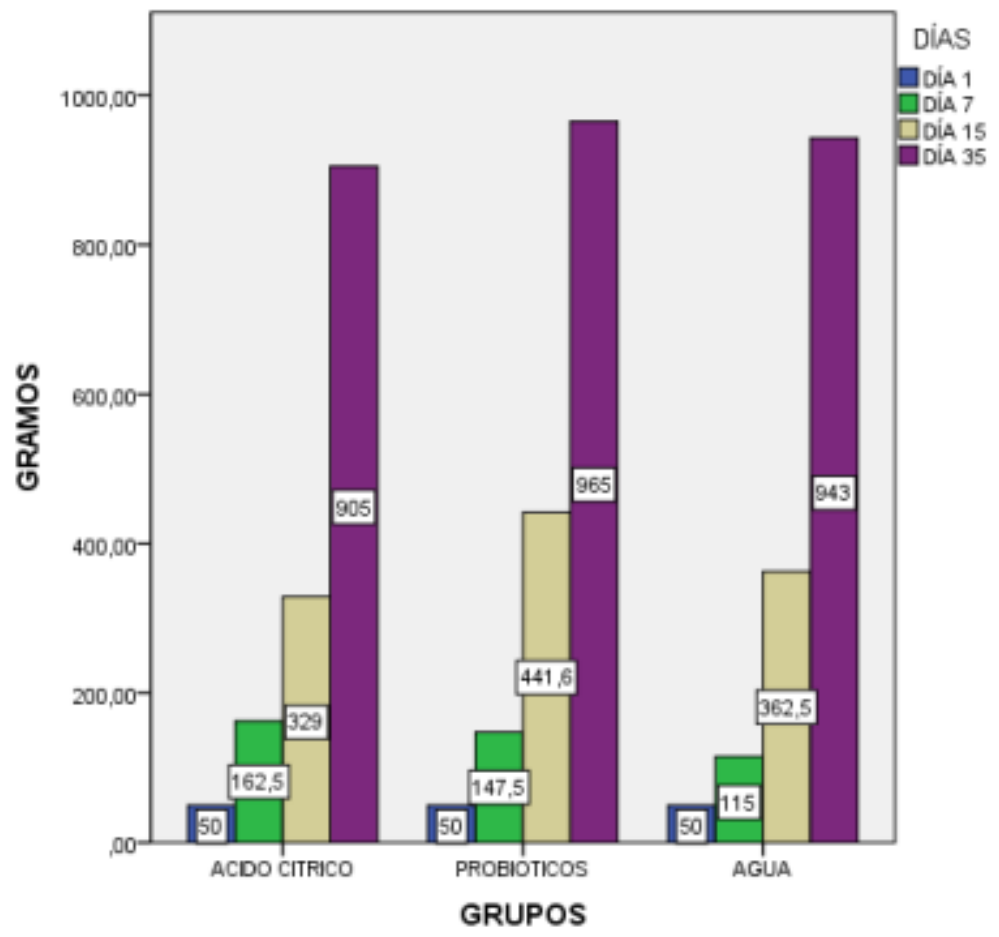

Figura 5. Promedio de la amplitud de las vellosidades duodenales en pollos de engorde 


\section{Discusión}

En este estudio, se encontró que las aves del grupo con suministro de solo agua, en el día uno de edad, presentan un leve retraso en el desarrollo pos-eclosión de las vellosidades duodenales; probablemente, porque no se ingirieron los nutrientes suficientes del líquido amniótico hacia el día 15 de incubación; en consecuencia, no se estimulan las enzimas digestivas que hacen posible la nutrición en la pre incubación (Aires et al., 2006). Otro factor que podría influenciar en el desarrollo poseclosión, es la presencia de ombligos pequeños en el momento del nacimiento, siendo este un indicativo de alteración en la absorción del contenido del saco vitelino residual y por consiguiente, el desarrollo de las vellosidades intestinales (Kawalilak, et al., 2010). Además, cuando se presenta demora en el suministro de alimento se observa disminución de fluidos, por tanto cierto grado de deshidratación, viéndose afectada de esta manera la longitud de las vellosidades y la superficie de absorción. (Maiorka, et al., 2003).

Nilipour (2007) indicó que los niveles de estrés en el lote de reproductoras, lleva a estados de inmunosupresión, el cual genera un mayor gasto de nutrientes con lo que se pone en riesgo la disponibilidad de dichos nutrientes al embrión, afectando la calidad del pollo y por ende, el desarrollo del tracto gastrointestinal pos-eclosión.

En el primer día de edad, las vellosidades analizadas en este estudio, se presentaron cortas, numerosas y de tamaño homogéneo. Se observó que en el tracto gastrointestinal de las aves una gran cantidad de criptas de Lieberküngh, lo que coincide con el estudio de Balamuguram et al., (2011) donde indicaron que esto favorece el desarrollo pos eclosión de la mucosa intestinal.

Al séptimo día de edad, las vellosidades de las aves del grupo suplementado con probiótico, se mostraron cortas y delgadas (Figura 2), ya que estas sustancias tienen la capacidad de competir con los microorganismos patógenos presentes en la mucosa intestinal, la estimulación inmune y la alteración del pH, lo que mejora el equilibrio microbiano, para permitir la absorción de nutrientes e intervenir en la regeneración de la mucosa intestinal, aumentando la longitud de las vellosidades intestinales. El uso de Probióticos del género Lactobacillus sp, reportó en investigaciones previas, mayor desarrollo de la altura de las vellosidades intestinales a nivel duodenal. (Fonseca, et al., 2010; Carneiro, 2008; Awad, et al., 2008; Pelícano, et al., 2003; Pelícano, et al., 2005; Awad, et al., 2009)

Respecto a las aves tratadas con ácido cítrico, la vellosidades se presentaron más amplias; lo que coincide con lo reportado por Viola y Viera, (2007), cuando se acidifica el medio intestinal, se beneficia el control de microorganismos patógenos, favoreciendo la estructura de las vellosidades intestinales; ya que los ácidos orgánicos en este caso -el ácido cítrico- actúa como fuente de energía disponible a nivel de los enterocitos, indicando mejor el desarrollo longitudinal de las vellosidades; lo que permite mayor área de absorción de los nutrientes. En cambio para el grupo suplementado con probiótico se presentaron más largas, pero sin uniformidad en la disposición de las mismas.

En el periodo comprendido del día 1 hasta el 7 de edad, las disposición de las vellosidades en los tratamientos propuestos se hizo en forma de zigzag, permitiendo la absorción más eficiente de los nutrientes. Esto debido a que el paso de los alimentos, a través del tubo digestivo, tarda más que cuando las vellosidades están dispuestas en forma de lengüeta, posibilitando mejor la absorción de los nutrientes (Pelicano et al., 2003 y 2005).

En cuanto al número de vellosidades entre los

Efectos de la adición de ácido cítrico y un probiótico comercial en el agua de bebida, sobre la morfometría del duodeno y parámetros zootécnicos en pollo de engorde 
días 7 y 15 de edad, en los tratamientos con ácido cítrico y agua, la mayor cantidad se debe -probablemente- a que la cantidad y el tamaño de las vellosidades depende del número de células (enterocitos) que la componen, por lo tanto, a mayor cantidad de células, de mejor tamaño se presentarán la vellosidades. En consecuencia, mayor será el área de absorción de nutrientes. (Furlan, et al., 2004).

Al final del periodo, las aves que fueron suplementadas con probióticos presentaron una mayor longitud y cantidad de vellosidades (Figura 3), seguido del tratamiento control, además, el número de vellosidades disminuyó respecto al día 15 de edad pero el tamaño aumentó. Los cambios en la cantidad y longitud de las vellosidades se explican por la acción trófica de los probióticos. Dado a que se estimula el proceso mitótico en la región cripta- vellosidad y a través de la exclusión competitiva, permitiendo mecanismos de proliferación en la mucosa intestinal (Furlan, etal., 2004).

La ganancia de peso semanal, en el periodo comprendido entre los días 1 y 15 de edad, fue de manera lenta, posiblemente porque durante este periodo se desarrollan los órganos intestinales; recibiendo por una parte las inmunoglobulinas, nutrientes del saco vitelino, y por otra, los del concentrado. Éstos cambios se presentan entre los días 4 y 10 de edad (Alves, et al., 2005). A partir del día 15 de edad se verifica -en el presente estudio- lo encontrado por Mendes, et al., (2010), donde se evidencia una etapa de crecimiento en las aves ya que los órganos internos están desarrollados y por ende, hay un mejor aprovechamiento de los nutrientes.

La ganancia de peso en el día 35 de edad, presentó mejor comportamiento productivo con la adición de probiótico frente a los otros grupos de estudio, debido posiblemente a que los probióticos tienen la capacidad de fermentar los azúcares simples, estimulando la producción de enzimas y ácido láctico, lo que se traduce en un mejor aprovechamiento de los nutrientes. Cuando entran en contacto con las membranas mucosas, tienen propiedades de ser anti-inflamatorias, antagonizar los gérmenes de putrefacción y / o agentes patógenos y facilitar el proceso digestivo (Reza, et al., 2010, Jardines, 2009).

\section{Conclusión}

Para el estudio anterior se puede concluir que el uso de sustancias orgánicas como el ácido cítrico y los probióticos, mejora el desarrollo alométrico de cantidad, longitud y amplitud pos-eclosión de las vellosidades duodenales, lo que se refleja en una mejor ganancia de peso al final del ciclo productivo del pollo de engorde.

\section{Referencias}

Aires PA, Silva CL, Ludovico AK, Moyica LN, Barcellos CM y Stringhini JH. "Inoculação de Nutrientes em Ovos de Matrizes Pesadas". R Bras Zootec. 2006; 35(5): 2018-2026.

Alves F, Machado- J, Buenos A, Nogueira A, Calil A, Gaiotto J, Berti J. "Diferentes Fontes de Proteína na Dieta Pré-Inicial de Frangos de Corte" . R Bras Zootec. 2005; 34(1): 112122.

Anjum M, Khan A, Azim A, y Afzal M,. "Effect of Dietary Supplementation of Multistrain Probiotic on Broiler Growth Performance". Pakistan Vet J. 2005; 25(1): 25-29.

Awad W, Ghareeb K, Abdel-Raheem S, and Böhm J. "Effects of dietary inclusion of probiotic and synbiotic on growth performance, organ weights, and intestinal histomorphology of broiler chickens". Poul 
Sci. 2009; 88:49-55.

Awad W, Gharib K, Böhm J. "Intestinal Structure and Function of Broiler Chickens on Diets Supplemented with a Synbiotic Containing Enterococcus faecium and Oligosaccharides". Int J Mol SCi. 2008; 9(11): 2205-2216.

Balamurugan R, y Chandrasekaran K. "Effects of Multi-enzyme Supplementation on Gut Morphology and Histomorphology in Broilers". Indian J Sci And Technol. 2011; 4(1): 15-18.

Carneiro A, 2008. "Probióticos na Raçao de Frangos de Corte e sua Influencia no Ph do Ingluvio e na Microbiota Intestinal". [Fecha de acceso: 3 de febrero de 2013]. URL: http:// www. bdtd .ufu. br/tde busca/ arquivo. php?codArquivo $=2019$.

Chowdhury R, Islam $M$, Khan $M$, Karim M, Haque M, Khatun and Pesti M, 2009. "Effect of citric acid, avilamycin, and their combination on the performance, tibia ash, and immune status of broilers". Poult Sci 88 (8): 1616-1622.

Fonseca B, Beletti $M$, Silva $M$, Silva $P$, Duarte I, Rossi D. "Microbiota of the Cecum, Ileum Morphometry, $\mathrm{PH}$ of the Crop and Performance of Broiler Chickens Supplemented with Probiotics". R Bras Zootec. 2010; 39(8):1756-1760.

Furlan R, Macari M, Luguetti C, 2004. "Como Avaliar os Efeitos do Uso de Prebióticos Probióticos e Flora de Exclusão Competitiva". [Fecha de acceso: 12 de febrero de 2013]. URL:http://www.cnpsa. embrapa.br/sgc/sgc_publicacoes/anais100 4_acave_furlan.pdf

Gauthier R, 2002. "La salud intestinal: Clave de la productividad - El caso de los ácidos orgánicos". [Fecha de acceso: 12 de febrero de 2013]. URL: http: // www .engormix .com /MA- avicultura/ nutrición /artículos /salud -intestinal-clave-productividadt518/p0.htm.

Gómez G, Hernández L, 2009. "Evaluación de la eficiencia de tres niveles de inclusión de acidificante Acidtek Av en la mortalidad, consumo de alimento, ganancia de peso e índice de conversión en aves de génetica ross en granja experimental de Colombia". [Fecha de acceso: 12 de febrero de 2013]. URL: http://www.engormix.com/MAavicultura/nutricion/foros/articuloevaluacion-eficiencia-tres-t17937/141p0.htm

González J, 2010. "Influencia de algunas características de composición de ingredientes alimenticios, en la productividad del broiler". [Fecha de acceso: 14 de febrero de 2013]. URL: www.veterinaria.uchile.cl/publicacion/con gresoxi/prafesional/aves/3.doc

Ignatova M, Sredkova V, Marasheva V. "Effect of Dietary Inclusion of Probiotic on Chickens Performance and Some Blood Indices". Biotech Anim Hus. 2009; 25(5-6): 1079-1085.

Jardines A, 2009. "Probióticos en Aves". [Fecha de acceso: 14 de febrero de 2013]. URL: http://www.d2-csl.it/allegati/ probiotici.pdf.

Kawalilak A, Ulmer F, Fasenko M. "Impaired Intestinal Villi Growth in Broiler Chicks with Unhealed Navels". Poult Sci. 2010; 89(1): 82-87.

Khambualai O, Yamauchi K, Jassada K, Incharoen T, Kashimura T. "Effect of Sugar Cane Extract, Commercial Probiotic and their Mixture on Growth Performance and Intestinal Histology in Broiler Chickens". Am J Anim Vet Sci 2010; 5(2): 132-138. 
Lessard M, 2004. "El uso de probióticos: Potencial de la salud del intestino". [Fecha de acceso: 14 de febrero de 2013]. URL: http://www.agrireseau.qc.ca/porc/docume nts/Lessard_Martin.pdf

Maiorka A, Santín F, Dahlke I, Furlan R, Macari M. "Posthatching Water and Feed Posthatching Water and Feed Gastrointestinal Tract and Intestinal Mucosa Development of Broiler Chicks. J Appl Poult Res. 2003; 12: 483-492.

Mendes T, Martins M, Komoyama C, Milbradt E. 2010. "Development Of Intestinal Tract On Broiler Chicken Feeding With High Density Nutrition". [Fecha de acceso: 14 de f e bre ro d e $\left.\quad \begin{array}{llllll} & 0 & 1 & 3\end{array}\right]$. U R L : http://www.prope.unesp.br/xxi_cic/27_38 341986841.pdf

Millán G, Pérez M, Puentes Y, Bocourt R. "Empleo de probióticos a base de Bacillus sp y sus endosporas en la producción avícola". Rev Cub Ci Agr. 2007; 42(2): 117-122.

Nilipour A, 2007. "La Alimentación de las Reproductoras". [Fecha de acceso: 18 de f e b re r o d e $\left.\quad \begin{array}{lllllll}2 & 0 & 1 & 3\end{array}\right]$. U R L : http://www.wattagnet.com/articles/3041la-alimentacion-de-las-reproductoras

Palencia S, Céspedes L, Nuviola Y. "La Cepa de Yogur como Probiótico, una Alternativa en la Salud y Mejora del Ternero". REDVET. 2005; 6(9): 1-35.

Pelicano E, Alves P, Borda H, Oba A, Norkus E. "Morfometría y Ultra-Estructura de la Mucosa Intestinal de Pollos de Engorde Alimentados con Dietas que Tienen Diferentes Probióticos". Revista Portuguesa de Ciencias Veterinarias. 2003; 98(547): 125-134.

Pelicano E, Souza P, Souza H, Figueiredo D, Boiago M, Carvalho S, Bordon V. "Intestinal
Mucosa Development in Broiler Chickens Fed Natural Growth Promoters". Braz J Poult Sci. 2005; 7(4): 221-229.

Ramírez I, Blanco D, 2009. "Utilización del acido acético y orégano en la regulación del ecosistema intestinal de aves de corral". [Fecha de acceso: 18 de febrero de 201]. URL: http:// www. adiveter. com/ftp /articles/ A227 0309.pdf.

Reza TH, Moravej $\mathrm{H}$, Ahmad M, Fatemeh T, Zaghari M, Shivazad M, Adibmoradi M. "Efficacy of Pediococcus acidlactici- based probiotic on intestinal Coliforms and villus height, serum cholesterol level and performance of broiler chickens". Afri J Biothecnol. 2010; 9(44): 7564-7567.

Saikat S, Sudipto H, Ghosh K. 2009. Eficacia comparativa de un ácido orgánico mezcla y Bacitracina Metileno Disalicy late como promotores del crecimiento en pollos de engorde: efectos sobre el rendimiento, Histología, y el medio del intestino delgado, La Medicina Veterinaria Internacional, Tomo 2010 (2010), Artículo ID 645150: 8.

Sarker K, Ri-Parque A, Kim G, Chul-Ju Y. "Alternativa a los antibióticos para la producción de pollos de engorde". Diario de Plantas Medicinales de Investigación. 2010; 4(5):415-420.

Sell J, 2009. "Nutrición y Alimentación de Aves". [Fecha de acceso: 18 de febrero de 2013]. URL: http:// www. midiatecavipec. com/nutricion/ Nutrici\%F3n\%20 Animal.pdf.

Viola E, Vieira S. "Suplementação de Acidificantes Orgânicos e Inorgânicos em Dietas para Frangos de Corte: Desempenho Zootécnico e Morfologia Intestinal". R Bras Zootec. 2007; 36(4):1097-1104. 